\title{
THE NATIONAL INTERESTS OF THE RUSSIAN FEDERATION IN THE AGRICULTURAL SPHERE AND THEIR REFLECTION IN THE NEW FOOD SECURITY DOCTRINE
}

\author{
Yuri A. Bokov \\ Volgograd State University, Volgograd, Russian Federation
}

Artem Yu. Mokhov

Volgograd Institute of Management - Branch of the Russian Presidential Academy of National Economy and Public Administration, Volgograd, Russian Federation

Introduction: the changes in the social and economic situation in recent years and the sanctions policy towards the Russian Federation require adjustments to the main strategic interests and priorities of the Russian state's policy in the field of agro-industrial complex and ensuring the country's food security. The purpose of the work is to identify the main factors that influence the formation of new principles and interests of the state in the field of food security, their reflection in the basic documents on ensuring the national security of the Russian Federation. The methodological framework for the study is the method of scientific analysis, as well as the comparative method. The result of the research is to determine the main trends in the legal support of food security in the context of the constitutional and agrarian legislation reform. Conclusions: in comparison with the previous documents, it is concluded that the list of the state interests, goals and objectives in the field of agriculture is enlarged by strengthening the requirements of social security and social protection, as well as expanding national agricultural production in order to achieve a state of food independence, ensuring the export policy. In the context of the July 2020 decisions the all-Russian vote on Amendments to the Constitution of the Russian Federation justifies the increased importance of food security issues, creating conditions for improving the standard of living of citizens, social obligations of the state in the field of agriculture, and sustainable development of rural territories. It is pointed out that it is necessary to take into account the requirements of environmental safety in the strategic planning in the agri-food sector. Doctrine.

Key words: national security, food security, agro-industrial complex, sustainable development, Food Security

Citation. Bokov Yu.A., Mokhov A.Yu. The National Interests of the Russian Federation in the Agricultural Sphere and Their Reflection in the New Food Security Doctrine. Legal Concept, 2020, vol. 19, no. 3, pp. 60-66. (in Russian). DOI: https://doi.org/10.15688/lc.jvolsu.2020.3.8

\section{НАЦИОНАЛЬНЫЕ ИНТЕРЕСЫ РОССИЙСКОЙ ФЕДЕРАЦИИ В АГРАРНОЙ СФЕРЕ И ИХ ОТРАЖЕНИЕ В НОВОЙ ДОКТРИНЕ ПРОДОВОЛЬСТВЕННОЙ БЕЗОПАСНОСТИ}

\author{
Юрий Александрович Боков
}

Волгоградский государственный университет, г. Волгоград, Российская Федерация

\section{Артем Юрьевич Мохов}

Волгоградский институт управления - филиал Российской академии народного хозяйства и государственной службы при Президенте РФ, г. Волгоград, Российская Федерация 
Введение: изменение социальной и экономической обстановки в последние годы, санкционная политика в отношении Российской Федерации требуют корректировки основных стратегических интересов и приоритетов политики российского государства в области агропромышленного комплекса и обеспечения продовольственной безопасности страны. Целью настоящей работы является выявление основных факторов, влияющих на формирование новых принципов и интересов государства в области обеспечения продовольственной безопасности, их отражение в базовых документах по обеспечению национальной безопасности Российской Федерации. Методологическую основу работы составляют метод научного анализа, а также сравнительный метод. Результатом проведенного исследования является определение основных тенденций правового обеспечения продовольственной безопасности в условиях реформирования конституционного и аграрного законодательства. Выводы: в сравнении с ранее действовавшими документами делается вывод о расширении перечня государственных интересов, целей и задач в области АПК за счет усиления требований социального обеспечения и социальной защиты, а также расширения национального сельскохозяйственного производства с целью достижения состояния продовольственной независимости, обеспечения экспортной политики. В контексте принятых в июле 2020 г. на общероссийском голосовании поправок в Конституцию Российской Федерации обосновывается повышенная значимость вопросов продовольственного обеспечения, формирования условий для повышения уровня жизни граждан, социальных обязательств государства в области сельского хозяйства, устойчивого развития сельских территорий. Указывается на необходимость учета требований экологической безопасности при стратегическом планировании в агропродовольственной сфере.

Ключевые слова: национальная безопасность, продовольственная безопасность, агропромышленный комплекс, устойчивое развитие, Доктрина продовольственной безопасности.

Цитирование. Боков Ю. А., Мохов А. Ю. Национальные интересы Российской Федерации в аграрной сфере и их отражение в новой доктрине продовольственной безопасности // Legal Concept = Правовая парадигма. -2020. - T. 19, № 3. -C. 60-66. -DOI: https://doi.org/10.15688/lc.jvolsu.2020.3.8

\section{Введение}

Для состояния рыночной экономики, провозглашенной на конституционном уровне свободы экономической деятельности, многообразия форм собственности (в том числе и на землю), вопросы сельского хозяйства, обеспечения населения достаточным количеством продовольствия по доступным ценам сохраняют свою актуальность и для современного управления народным хозяйством в Российской Федерации. Традиционно высокая для нашей страны роль аграрной сферы, значительное количество сельского населения, а также экспортная ориентированность экономики постоянно требуют от государства выработки и применения наиболее эффективных (не только с экономической, но и социальной точки зрения) мер по регулированию и поддержке отечественных сельхозтоваропроизводителей, а также повышения и поддержания достойных условий жизни на селе. Кроме того, кризисные экономические ситуации (к которым можно с уверенностью отнести преодоление негативных последствий пандемии COVID-19, оценка которых в том числе и связанных с занятостью в сельской местности, повышением уровня цен на продовольственные товары и т. д. - еще окончательно не произведена) обусловливают необходимость определенного «запаса прочности» финансовых и организационных средств, прежде всего связанных с созданием и нормальным функционированием системы продовольственных резервов, разумной экспортной политикой, государственным вмешательством в ценообразование на наиболее важные категории продуктов питания.

\section{Современные вызовы и продовольственная безопасность страны}

Стоит согласиться с авторами, отмечающими, что, несмотря на переход к постиндустриальному этапу развития, практически во всех современных государствах агропродовольственная проблема остается актуальной, соединяя в себе «узловые проблемы проведения агропромышленной и экономической реформ, реальные тенденции развития производства сельскохозяйственной и продовольственной продукции отечественного рынка, изменения степени его зависимости от мирового рынка продовольствия, социального положения, 
платежеспособности России в целом и потребителей различных регионов» [7, с. 69]. Все эти вопросы должны быть отражены на соответствующем законодательном уровне, находить свою реализацию и исполнение в подзаконных актах на федеральном, региональном и местном уровнях, складываясь в итоге в единую систему мер по обеспечению продовольственной безопасности страны. Принятие в июле 2020 г. поправок в Конституцию Российской Федерации, многие из которых закрепляют на уровне Основного закона целый ряд социальных обязательств государства, подробно раскрывают механизмы реализации и гарантирования целого ряда прав и свобод личности, придают повышенную значимость вопросам защиты базовых прав человека, одним из которых, пусть прямо и незакрепленным в нашей стране конституционно, является право на питание. Как отмечается в современных исследованиях, «потребляемое человеком питание говорит о качестве и уровне жизни в этом государстве, ввиду чего государства ставят перед собой задачу по защите прав человека на питание» [2, с. 110]. «Создание условий для повышения благосостояния граждан» - принципиальная задача Российского государства, имеющая базовое конституционное значение (ст. 75.1 Конституции).

Неоднозначная внешнеэкономическая ситуация, обусловленная давлением на Российскую Федерацию со стороны иностранных государств путем введения санкций, «контр-санкционные» ответные мероприятия российской стороны, связанные с запретами и ограничениями на ввоз сельскохозяйственной продукции и продуктов питания из целого ряда стран, обусловили необходимость выработки нового подхода к соотношению экспортной и импортной составляющих в отечественной сельскохозяйственной отрасли, корректировкой их «содержания». Это также потребовало изменений нормативно-правовой базы регулирования отношений в области продовольственной безопасности.

Причиной постоянного мониторинга состояния законодательства о сельском хозяйстве и продовольственной безопасности, принятия новых и изменения уже существующих правовых актов выступают также и глобальные проблемы, в той или иной степени влияющие на состояние природных ресурсов, конъ- юнктуру производственной и потребительской сфер экономики. К числу основных глобальных проблем современности, негативно влияющих на состояние сельского хозяйства и продовольственной безопасности в мире, современные исследователи относят уменьшение подходящих для обработки качественных земель сельскохозяйственного назначения с одновременным уменьшением пригодных для пастбищного скотоводства площадей; недостачи со снабжением всего населения пресной водой и основными видами продуктов питания; объективная невозможность повышения урожайности основных выращиваемых сельскохозяйственных культур (что вызывает опасения в обстановке увеличения численности населения и роста количества необходимых для удовлетворения их потребности в питании продуктов), а также общее ухудшение экологической ситуации, влияющее, прежде всего, на состояние почв, влекущее их засорение, засоление, и иные факторы, обусловливающие снижение их урожайности [1, с. 9].

Процессы информатизации общества, а также повышения роли современных коммуникаций даже в такой «консервативной» сфеpe, как сельское хозяйство, также должны быть связаны с надлежащими источниками их правового регулирования. Как представляется, данный процесс должен быть осуществлен в контексте развития общефедеральных систем «электронного правительства», разработки отечественного программного обеспечения - в том числе направленного на повышение производительности АПК Российской Федерации на основе информационных средств. В связи с этим необходимо отметить реализуемую на территории РФ с 2019 г. Федеральную программу «Цифровое сельское хозяйство», главным преимуществом которой, как отмечают исследователи, является «создание возможности для массового внедрения комплексных цифровых агрорешений, а также получение цифровых компетенций специалистами сельскохозяйственных предприятий страны» [6, с. 89]. Кроме того, единообразное регулирование использования современных технологий в сельскохозяйственном производстве поспособствует организации контроля в использовании отдельных технологических средств (например, беспилотных 
летательных аппаратов), а также отнесенному поправками 2020 г. к исключительной компетенции Российской Федерации по «обеспечению безопасности личности, общества и государства при использовании информационных технологий» (п. «м» ст. 71 Конституции).

Таким образом, к концу 2010-х гг. законодателем была осознана реальная необходимость принятия нового акта в области продовольственной безопасности, который соответствовал бы всем изменяющимся объективным факторам:

- конкретизация социальных обязательств государства на международном и национальном конституционном уровнях;

- изменение внешнеэкономической ситуации, корректировка экспортной и импортной политики;

- влияние глобальных экологических, экономических и социальных проблем, требующих участия Российской Федерации в глобальной и региональной системах продовольственной безопасности, с одновременным сохранением собственных политических и финансовых интересов.

\section{Отражение стратегических задач и приоритетов в области продовольственной безопасности в 2020 году}

В связи с этим 21 января 2020 г. Указом Президента № 20 была утверждена новая Доктрина продовольственной безопасности Российской Федерации, которая заменила собой другую, действовавшую с 2010 г., Доктрину (утв. Указом Президента РФ от 30.01.2010 № 120). Доктрина не является нормативным правовым актом в «общепринятом» смысле этого слова, представляя собой документ стратегического планирования. Документы (акты) стратегического планирования представляют собой специфические политико-программные документы, которыми обозначаются основные приоритеты, цели и задачи деятельности органов публичной власти в определенных сферах. Порядок принятия актов стратегического планирования, основные предъявляемые к ним требования закреплены в специальном Федеральном законе «О стратегическом планировании в Российс- кой Федерации» от 28.06.2014 № 172-Ф3. Кроме того, Доктрину продовольственной безопасности можно отнести к специальной разновидности актов стратегического планирования - «документам в сфере обеспечения национальной безопасности Российской Федерации» (п. 25 ст. 3 Ф3 «О стратегическом планировании»). По мнению А.В. Малько, документы в области стратегического планирования представляют собой, прежде всего, акты доктринального характера, при помощи которых обозначены главные приоритеты правовой политики страны; такие акты «предшествуют принятию серии правовых актов различных видов, предназначенных для реализации перспективных преобразований» [5, с. 16].

В сравнении с аналогичным документом 2010 г. новой Доктриной закреплено новое определение «продовольственной безопасности». Раньше она представляла собой «состояние экономики страны», пусть и обеспечивающее целый ряд социальных факторов (ст. 5 Доктрины 2010 г.). Однако на сегодняшний день продовольственная безопасность - это «состояние социально-экономического развития», гарантирующее не только продовольственную независимость страны (которая выражается в уровне самообеспеченности национальной потребности в продуктах питания за счет отечественного сельского хозяйства и пищевой промышленности), но и фактический доступ каждого гражданина к качественному продовольствию по доступным ценам (ст. 1 Доктрины 2020 г.); целью мер по обеспечению продовольственной безопасности также является и поддержание здорового и активного уровня жизни, обеспечивающего экономическую активность гражданина, его полноценное участие в общественной жизни страны.

Данный факт указывает, на наш взгляд, на «встраивание» продовольственной безопасности в общую систему мер по обеспечению национальной безопасности Российской Федерации (снабжение наиболее нуждающихся слоев населения в порядке внутренней продовольственной помощи, поставка продовольствия в образовательные, медицинские и социальные учреждения, снабжение Вооруженных Сил и правоохранительных органов), поскольку концепт «национальная безопасность» рассматривается как в теории, так и на нормативном 
уровне как «симбиоз» экономических, организационных, правовых и социальных средств с преобладанием последних; единый принцип для всех отраслей правовой системы [4, с. 45]. Данное положение прямо соответствует конституционному принципу приоритета прав и свобод личности как высшей ценности любой деятельности органов и должностных лиц публичной власти (ст. 2, 17 Конституции РФ).

Новой Доктриной закреплен целый перечень национальных интересов в области обеспечения продовольственной безопасности Российской Федерации (п. 7). В сравнении с ранее действовавшим документом, где были перечислены только задачи государства в области аграрного и продовольственного развития (всего четыре), Доктрина 2020 г. указывает на двенадцать стратегических интересов деятельности по обеспечению продовольственной безопасности. Данные интересы можно классифицировать на три большие группы сообразно приведенным выше факторам реформирования законодательной базы продовольственной безопасности страны: вития.

1. Интересы в области социального раз-

2. Интересы, связанные с совершенствованием сельского хозяйства как отрасли национальной экономики страны.

3. Экономические интересы Российской Федерации в агропродовольственной сфере.

В отличие от Доктрины 2010 г., где были обозначены только задачи в области агропродовольственной политики без их подробного толкования и взаимосвязи с иными актами стратегического планирования, действующим документом указывается на взаимосвязь интересов Российской Федерации в сфере продовольственной безопасности с учетом требований Стратегии национальной безопасности РФ (утв. Указом Президента № 683 от 31.12.2015), что указывает на стабильность в области доступа граждан к качественному и достаточному продовольствию как на необходимое условие для сохранения безопасности нашей страны в целом. Действительно, здесь можно отметить исторически обусловленную взаимосвязь продовольственной безопасности и безопасности социальной, так как многие общественные волнения были связаны (или прямо спровоцированы) перебоями в постав- ках продовольствия. Таким образом, взаимосвязь положений Доктрины 2020 г. с общими документами в области национальной безопасности страны представляется верной не только с точки зрения юридической техники и выстраивания иерархии актов стратегического планирования, но и в идеологическом аспекте, поскольку тем самым указывается на продовольственную стабильность, устойчивое развитие сельскохозяйственной отрасли как имманентно присущую всему государству цель экономического и социального управления.

В свою очередь, нужно отметить отсутствие указания на экологические критерии обеспечения продовольственной безопасности как стратегические интересы государственной политики. При этом состояние окружающей среды непосредственно влияет, прежде всего, на состояние почв и земель сельскохозяйственного назначения. Учеными справедливо указывается на взаимодействие продовольственной и экологической безопасности, общность задач и целей соответствующих мероприятий. При этом нередки ситуации, когда меры, направленные на интенсификацию сельскохозяйственного производства (то есть обеспечение продовольственной безопасности), оказывают негативное воздействие на экосистему соответствующей теории, влекут за собой загрязнение природных объектов и истощение природных ресурсов (охрана и рациональное использование - уже целевые установки экологической безопасности). Например, при нерациональном использовании предоставленных ресурсов расширение пахотных площадей, рост количества пастбищ влекут за собой истощение почвы, разрушение сложившихся экологических связей между видами, вымывание и выдувание плодородного слоя [3, с. 81-82].

\section{Выводы}

Таким образом, дальнейшее развитие системы законодательного обеспечения продовольственной безопасности должно учитывать только требования по сохранению социальной стабильности, росту экономического благосостояния, интенсификации сельского хозяйства, предупреждая и устраняя угрозы в данной сфеpe. Аграрное законодательство должно способствовать также сохранению и приумножению 
природных богатств. Прежде всего, это касается земли как главной производственной «базы» сельского хозяйства; учет земли как основы жизни и деятельности народов Российской Федерации, основы для сельскохозяйственного производства является важнейшим основополагающим началом систем земельного и аграрного законодательства нашей страны. Предлагается обозначить приоритеты экологической стабильности как основы деятельности в сфере АПК в виде отдельного раздела Доктрины продовольственной безопасности РФ, где содержались бы основные агроэкологические и агроклиматические риски продовольственной безопасности, а также обозначалось бы распределение полномочий федеральных и региональных органов государственной власти в сфере соблюдения природоохранных требований в сельском хозяйстве. Необходимость четкого разделения компетенции в этой области (как и аграрном праве в целом) обусловливается внесением дополнения в п. «Д» ст. 72 Конституции, согласно которому к перечню сфер совместной компетенции РФ и ее субъектов отнесено теперь и сельское хозяйство.

\section{СПИСОК ЛИТЕРАТУРЫ}

1. Алтухов, А. И. Парадигма продовольственной безопасности России : монография / А. И. Алтухов. - М. : Фонд развития и поддержки молодежи «Кадровый резерв», 2019. -685 с.

2. Гаипова, В. Р. Реализация права на питание на муниципальном уровне: теоретико-правовой аспект / В. Р. Гаипова // Теория государства и права. 2019. - № 4. - C. 110-114.

3. Жевлаков, Г. Д. Продовольственная и экологическая устойчивость в обеспечении безопасности общества / Г. Д. Жевлаков // Азиатско-Тихоокеанский регион: экономика, политика, право. 2019. - № 1. - С. 79-95.

4. Ирошников, Д. В. Безопасность как правовой принцип / Д. В. Ирошников // Юридическая наука. - 2017. - № 3. - С. 41-45.

5. Малько, А. В. Доктринальные акты как основной инструмент правовой политики / А. В. Малько, Я. В. Гайворонская // Право. Журнал Высшей школы экономики. - 2018. - № 1. - С. 4-25.
6. Мирина, Н. В. О некоторых проблемах обеспечения продовольственной безопасности и путях их решения / Н. В. Мирина // Научный вестник Волгоградского филиала РАНХиГС. Серия: Юриспруденция. - 2019. - № 1. - С. 86-91.

7. Семенова, Н. Н. Обоснование продовольственной безопасности как важнейшего государственного приоритета / Н. Н. Семенова // Национальные интересы: приоритеты и безопасность. 2011. - № 37. - C. 69-76.

\section{REFERENCES}

1. Altuhov A.I. Paradigma prodovolstvennoy bezopasnosti Rossii [Russia's Food Security Paradigm]. Moscow, 2019. 685 p.

2. Gaipova V. R. Realizatsiya prava na pitanie na munitsipalnom urovne: teoretiko-pravovoy aspect [Realization of the Right to Food at the Municipal Level: Theoretical and Legal Aspect]. Teoriya gosudarstva i prava [Theory of State and Law], 2019, no. 4, pp. 110-114.

3. Zhevlakov G.D. Prodovolstvennaya i ekologicheskaya ustoychivost $\mathrm{v}$ obespechenii bezopasnosti obshhestva [Food and Environmental Sustainability in Ensuring Public Safety]. AziatskoTihookeanskiy region: ekonomika, politika, pravo [Asia Pacific: Economics, Politics, Law], 2019, no. 1, pp. 79-95.

4. Iroshnikov D.V. Bezopasnost kak pravovoy printsip [Security as a Legal Principle]. Juridicheskaya nauka [Law Science], 2017, no. 3, pp. 41-45.

5. Mal'ko A.V., Gajvoronskaja Ya.V. Doktrinalnye akty kak osnovnoy instrument pravovoy politiki [Doctrinal Acts as the Main Instrument of Legal Policy]. Pravo. Zhurnal Vysshey shkoly ekonomiki [Right. Journal of the Higher School of Economics], 2018, no. 1, pp. 4-25.

6. Mirina N.V. O nekotorykh problemakh obespecheniya prodovolstvennoy bezopasnosti i putyah ikh resheniya [On Some Problems of Ensuring Food Security and Ways to Solve Them]. Nauchnyy vestnik Volgogradskogo filiala RANHiGS. Seriya: Jurisprudentsiya [Scientific Bulletin of the Volgograd Branch of the RANEPA. Series: Law], 2019, no. 1, pp. 86-91.

7. Semjonova N.N. Obosnovanie prodovolstvennoy bezopasnosti kak vazhneyshego gosudarstvennogo prioriteta [Justification of Food Security as a Major State Priority]. Natsionalnye interesy: prioritety i bezopasnost [National Interests: Priorities and Security], 2011, no. 37, pp. 69-76. 


\section{ТЕОРИЯ И ПРАКТИКА ГОСУДАРСТВЕННО-ПРАВОВОГО РАЗВИТИЯ}

\section{Information About the Authors}

Yuri A. Bokov, Candidate of Sciences (Jurisprudence), Associate Professor, Department of Constitutional and Municipal Law, Volgograd State University, Prosp. Universitetsky, 100, 400062 Volgograd, Russian Federation, bokov@volsu.ru, https://orcid.org/0000-0001-6357-9599

Artem Yu. Mokhov, Assistant Lecturer, Department of Constitutional and Administrative Law, Volgograd Institute of Management - Branch of the Russian Presidential Academy of National Economy and Public Administration, Gagarina St, 8, 400131 Volgograd, Russian Federation, aumohov@mail.ru, https://orcid.org/0000-0003-0438-2467

\section{Информация об авторах}

Юрий Александрович Боков, кандидат юридических наук, доцент кафедры конституционного и муниципального права, Волгоградский государственный университет, просп. Университетский, 100, 400062 г. Волгоград, Российская Федерация, bokov@volsu.ru, https:/orcid.org/0000-0001-6357-9599

Артем Юрьевич Мохов, ассистент кафедры конституционного и административного права, Волгоградский институт управления - филиал Российской академии народного хозяйства и государственной службы при Президенте РФ, ул. Гагарина, 8, 400131 г. Волгоград, Российская Федерация, aumohov@mail.ru, https://orcid.org/0000-0003-0438-2467 